AperTO - Archivio Istituzionale Open Access dell'Università di Torino

\title{
A Contrastive Analysis of Reporting Clauses in Comparable and Translated Academic Texts in English and Italian
}

\section{This is the author's manuscript}

Original Citation:

Availability:

This version is available http://hdl.handle.net/2318/1558339

since 2018-12-19T15:09:40Z

Published version:

DOI:10.1075/lic.17.1.02mol

Terms of use:

Open Access

Anyone can freely access the full text of works made available as "Open Access". Works made available under a Creative Commons license can be used according to the terms and conditions of said license. Use of all other works requires consent of the right holder (author or publisher) if not exempted from copyright protection by the applicable law. 


\title{
A contrastive analysis of reporting clauses in comparable and translated academic texts in English and Italian
}

\author{
Alessandra Molino \\ University of Turin (Italy)
}

This article investigates the use of finite reporting clauses with that-clause complementation (e.g. I will suggest that...) as devices for the expression of stance in academic texts (Hyland and Tse 2005; Charles 2006). These constructions are compared to their functional equivalents in Italian, i.e. reporting clauses with che ('that') complementiser. The comparison is carried out using a corpus-based approach, involving the analysis of a parallel corpus of Political Science papers in English and their translations into Italian, as well as a comparable corpus of articles originally written in Italian within the same discipline. Thanks to their ability to convey evaluative meanings, reporting clauses are analysed as structures that may provide insights into the epistemological negotiations taking place in the encounter of different research traditions through the practice of translation.

Keywords: reporting clauses, academic writing, translation, epistemology, corpus-based approach, English/Italian

\section{Introduction}

This article explores the use of finite reporting clauses with that-clause complementation (e.g. the evidence shows that...) as devices for the expression of writer stance in academic prose (Hyland and Tse 2005; Charles 2006). These constructions are compared to their functional equivalents in Italian, i.e. the socalled 'soggettive' and 'completive oggettive' (see section 3), namely subordinate clauses introduced by the complementiser che ('that', henceforth che-clauses for ease of reference). The approach is discourse analytical and draws on the rich literature of academic discourse across languages and cultures (Martínez 2005; Mur Dueñas 2007; Suárez and Moreno 2008; Molino 2010; Peréz-Llantada 2012). Therefore, patterns of use are described and related to factors such as academic writing traditions and epistemology in the attempt to explain why comparable constructions in the two languages are used in different ways.

This study also considers translated academic texts from English into Italian. Academic translation is often seen as a neutral social practice and translated academic texts are perceived as factual descriptions of reality. This view, as Bennett (2007) notes, is associated with the idea that academic translation is mainly a matter of terminological accuracy. In this paper, this idea will be challenged and the hypothesis will be tested that thanks to their ability to convey evaluative meanings, reporting clauses are structures that provide 
insights into the epistemological negotiations taking place in the encounter of different research traditions.

The materials used in this study include a comparable corpus of twenty research articles, i.e. ten per language, in the field of Political Studies, and the translations of the English papers into Italian. By taking a corpus-based approach, translated texts will not be investigated "in terms of [their] equivalence to source texts but as [...] valid object[s] of study in [their] own right" (Olohan and Baker 2000:141). Therefore, the interest lies in the implications of recurrent patterns in the three sets of texts, considered as autonomous entities in the communicative contexts in which they operate.

\section{Reporting that-clauses, writer stance and epistemology}

Numerous studies (e.g. Charles 2006; Dressen 2003; MacDonald 1994) have shown that academics use language in ways that reflect the epistemology of their discipline. Therefore, writers select lexico-grammatical resources that reflect the values according to which research is assessed in their discipline. The purpose is to seek acceptance for their claims so as to ascribe them the status of scientific knowledge.

That-clauses are extremely flexible structures to convey evaluative meanings thanks to the variety of predicates that can introduce them, i.e. verbs (suggest), nouns and noun phrases (the fact), and adjectives (interesting). This study is concerned with reporting verbs, as they are the most common type of predicate in English academic writing (Hyland and Tse 2005:124). Reporting clauses with that-clause complementation enable writers to express their stance towards the reported proposition by choosing a strategic combination of grammatical subject and reporting verb, as illustrated in examples (1)-(3).

(1) In fact, I will argue that the economic weaknesses of the model can in large measure be explained by the kind of political alliance that was required to support it $[\ldots]$. [SR5 $]^{1}$

(2) It will be suggested that the European Union could realize both these possibilities [...]. [SR6]

(3) [...] it cannot be denied that the ease with which unions were sidelined was partly due to some of their own choices [SR5]

These examples are all 'averrals' (Tadros 1993), namely claims originating from the writer. $^{2}$ However, these examples differ in a number of respects. In the first one, the writer explicitly attributes the claim to him/herself thus taking direct responsibility for it, as indicated by the choice of the personal pronoun $I$ in subject position. In the second and third examples, the writer opts for an impersonal construction, using the pronoun it as dummy subject followed by the passive voice. This choice has important interpersonal consequences as it provides claims with an objective orientation. Impersonality makes it more

\footnotetext{
${ }^{1}$ The labels in square brackets indicate the corpus (capital letters) and the text (number) from which each example is taken. See Section 3 for a detailed description of the parallel and comparable corpora used in this study. See Appendices A, B and C for the list of the articles included in the three corpora.

${ }^{2}$ Claims from other sources are called 'attributions' (Tadros 1993).
} 
difficult for readers to question the truth-value of the claim. This linguistic and rhetorical choice may reflect the epistemological view of the researcher as someone who reports facts using neutral observational language.

In examples (1)-(3), the choices made for the subject are counterbalanced by the selection of the reporting verb and the degree of certainty attached to the claim. In the first example, the verb argue presents the projected clause as an opinion that the writer is defending in the paper. The verb suggest in example (2) performs a similar function and frames the reported message not as a fact but as a tentative claim, hedging the force of the assertion. Finally, in example (3), the verb deny indicates the attention of the writer to the possible reaction of the readers. All these verbs are 'discourse acts' (Hyland 2000:27) and indicate that knowledge construction is viewed as a process that is advanced by taking up a position in relation to existing opinions and studies. This epistemological view reflects the preference for critical understanding and reinterpretation of an existing body of ideas, a process that is more typical of the Humanities and Social Sciences than the Natural Sciences (Becher 1981).

\section{Cross-linguistic observations}

Another reason for focusing on reporting clauses is their cross-linguistic comparability. In English there have been numerous studies on reporting thatclauses, in fields such as grammar (Elsness 1984; Thompson and Mulac 1991; Kaltenböck 2006), semantics (Dor 2005), language variation (Biber 1999), academic writing (Charles 2006) and translation (Olohan 2001, 2002). On the other hand, investigations of reporting clauses with che complementiser in Italian are less frequent (e.g. Wanner 1981) or carried out within wider research agendas (e.g. Calaresu 2004 on the textual and pragmatic implications of reported speech; and Murphy 2005 on attribution in news discourse from an English-Italian contrastive perspective). Therefore, in order to account for reporting clauses with che complementiser, and compare them to their corresponding English constructions, I will refer to the currently most authoritative Italian reference grammar, i.e. Renzi et al. (1991; 1995), in particular, to the sections by Acquaviva (1991) and the chapter by Mortara Garavelli (1995).

Reporting clauses with verbal predicate are structured in a similar way in English and Italian: they present a reporting verb followed by a complementiser (i.e. that/che), which introduces a subordinate clause featuring a finite verb. In both languages, subordinate clauses with a verbal predicate may function as subject (examples 4 and 5) or as direct object (examples 6 and 7).

(4) [...] then it follows that over any time period, no matter how short, every agent will incur either a monetary surplus or a deficit. [SR6] ${ }^{3}$

(5) Sembrerebbe che una parte significativa di queste spese sia da considerarsi produzione di merci base $[\ldots] .[\mathrm{CM} 4]^{4}$

\footnotetext{
${ }^{3}$ In English, the subordinate clause introduced by that functions as an extraposed subject with copular verbs such as appear and seem, the verb follow used intransitively, and the passive form of verbs such as find, know, assume, say and show (Biber et al. 1999:670).

${ }^{4}$ When an Italian subordinate clause functions as subject, the reporting verb belongs to the class of the so-called 'verbi impersonali' ('impersonal verbs'), such as sembrare ('seem') and parere ('appear') (Acquaviva 1995:665).
} 
"It would seem that a significant part of these expenditures is due to the production of basic goods [...]."

(6) But they do seem to have thought that, given the bourgeoisie's own declarations in favour of rapid development, they would cede to state managers the autonomy they needed [...]. [SR5]

(7) Burnham riconosceva il carattere transeunte del modo di produzione capitalistico, ma credeva che il socialismo non fosse affatto l'esito della sua crisi [...]. [CM9] ${ }^{5}$

"Burnham acknowledged the transitory character of capitalistic production, but he believed that it was not socialism the result of its crisis $[\ldots] . "$

Another similarity is the possibility in both languages to omit the complementiser. However, the conditions under which complementiser omission takes place are different. Numerous studies have shown that in English that-omission is a highly register-sensitive phenomenon. Elsness (1984), Biber (1999) and Kaltenböck (2006) have provided evidence that in academic prose only a marginal percentage of instances of reporting clauses present zero complementation. For instance, in Biber's (1999) study approximately 95\% of all the investigated instances retain that in academic prose, and in Kaltenböck (2006) complementiser omission only occurs in one per cent of the examined sentences in the same register. According to Biber, complementiser retention is due to the features of academic prose, which is characterized by "careful production circumstances; an expository, informational purpose; and a formal tone" (1999:145). In addition, academic prose is associated with the preference for a hypotactic style and a high degree of explicitness in structural links (Kaltenböck 2006:393). Finally, some scholars have argued that complementiser retention conveys a greater sense of detachment and objectivity (see Storms 1966; Dor 2005; Kaltenböck 2006), two traits often associated with scholarly writing.

With regard to Italian, Acquaviva (1995:644-645) attributes che/zero alternation to the choice of verb, and provides the following examples of items that can be found in both forms: capire ('understand'), credere ('believe'), dire ('say'), pensare ('think'), temere ('be afraid'), sperare ('hope'), escludere ('exclude'), immaginare ('imagine'), dubitare ('doubt'), ipotizzare ('hypothesise'), arguire ('infer/deduce'), dedurre ('infer/deduce'), concludere ('conclude'), supporre ('suppose'), pretendere ('claim/expect'), trovare ('find/think'). Many of these verbs are very common in academic writing; hence, it would be important to know whether che/zero alternation is registersensitive. However, to my knowledge, such variation has not been explored systematically in Italian. ${ }^{6}$ Therefore, in order to determine whether

\footnotetext{
${ }^{5}$ Italian subordinate clauses functioning as direct object are called 'completive oggettive' (Acquaviva 1995:633) and the reporting verb is typically a verb of saying (e.g. dire, 'say') or an epistemic verb (e.g. apprendere, 'know') (Acquaviva, 1995:643).

${ }^{6}$ The possible influence of register is hinted at in Wandruszka (1991:453), who suggests that when the main clause contains a verb of doubt and the subordinate clause features a subjunctive (e.g. dubito (che) sia facile, 'I doubt that it is easy'), che may be omitted, a choice that he associates mainly with literary registers.
} 
complementiser omission could significantly affect the quantitative data of this study, I ran concordances for each of the above-mentioned Italian verbs and checked whether they were followed by che or not. The results indicate that in the Italian corpora used in this study (see section 3 for detailed information) zero complementiser is only found in connection with the verbs of saying dire ('say') and concludere ('conclude'), and with the verb immaginare ('imagine'). Instances with zero complementiser constitute $6 \%$ of all the reporting clauses in the corpora and are employed in very specific circumstances, namely in parenthetical constructions (example 8) to allow the thematisation of the subject (i.e. Questo sovrappiù, 'This surplus') of the reported clause; and in embedded clauses where che is stylistically undesirable (in example 9 the complementiser che would be too close to the preceding relative pronoun, again che, and perceived as cacophonic).

(8) Questo sovrappiù, si dice comunemente, può essere individuato in termini di quantità fisiche [...]. [CM8]

"This surplus, as is commonly said, can be defined in terms of physical quantities [...]."

Cf. *Si dice comunemente che questo sovrappiù possa essere individuato in termini di [...].

"*It is commonly said that this surplus can be defined in terms of [...]."

(9) [...] per esempio nelle ditte che il pubblico immagina siano loro rivali [...]. [SRI7]

"[...] for instance in the firms that the public perceives as being their rival $[\ldots] . "$

Cf. * ${ }^{*}[.$.$] per esempio nelle ditte che il pubblico immagina che siano$ loro rivali $[\ldots]$.

"* [...] for instance in the firms that the public perceives that they are their rival $[\ldots] . "$

Given the paucity of cases of complementiser omission in both English and Italian, I decided to focus on structures with that and che retention, a choice that was deemed not to affect the description of reporting clauses in significant ways.

Another syntactic difference between English and Italian is that subject pronouns are normally not expressed in Italian because it is possible to identify person and number through verb endings.

Finally, there may be differences in the way impersonality is encoded, as in English the passive voice is more frequent than in Italian, where the so-called si forms are preferred (e.g. si può affermare che, 'one can affirm that'; see Section 3.3), but these divergences, as we shall see, do not impede comparison, as the functions performed by reporting clauses are the same in the two languages, i.e. to put forward knowledge claims (averral) and to report the claims of other discourse participants (attribution). Both functions are explored in the subsequent analysis. 


\section{Materials and methods}

\subsection{From Socialist Register to Socialist Register Italia}

The sources used to compile the parallel corpus are the Socialist Register (SR) and Socialist Register Italia (SRI). The Socialist Register is an authoritative international journal that has been publishing contributions on political, social and economic issues since 1964. It is a multidisciplinary journal and authors may be sociologists, anthropologists, political theorists and political economists. Despite the multiplicity of perspectives, all contributions present discussions from the standpoint of the independent new left.

In 2009, Adduci and Cerimele edited an anthology entitled Socialist Register Italia, which contains articles that originally appeared in the Socialist Register from 2001 to 2008. The papers selected for translation into Italian are considered by the editors representative of key issues in the international debate. More specifically, the Italian anthology comprises papers discussing theoretical issues, works applying Marxist criticism to specific geographical contexts and to the ecological perspective in Development Studies. In addition, the anthology includes three papers written for a symposium on 'Neoliberalism and the Left'.

The motivation behind Adduci and Cerimele's project was that little material was available in Italian discussing development issues from the standpoint of a Marxist critique to Neoliberalism, the only notable exception being the work of David Harvey, which had been translated into Italian. Therefore, the goal of the project was to make available for academics, students and political activists the most recent and influential discussions characterizing the international debate so as to create an active Italian network of intellectuals around the themes explored in the Socialist Register.

The texts were translated into Italian by a group of young researchers. Most of them had no permanent academic position, but worked on a contract basis; others were PhD students at various Italian universities. The editors, too, translated one text each. Some translators possessed relevant disciplinary knowledge, but they did not have translation experience; on the other hand, other translators were foreign language specialists, but lacked subject-specific competence. For this reason, the editors had to significantly revise the texts submitted by the translators in order to arrive at a publishable version (Adduci personal communication).

The translations included in Socialist Register Italia were chosen for analysis because the editors aimed at literally 'importing' the international debate of the new left, which they regarded as not being sufficiently well-known among the target audience. The goal of introducing new forms of knowledge is an interesting aspect to investigate as it may involve epistemic negotiations between different research traditions.

When interpreting results pertaining to the comparison between source and target texts, the following contextual aspects will be taken into account:

- Directionality: The texts are translated from English, the dominant language of academic research writing, into Italian, a language mainly used by native speakers within the national academic community;

- Status of translators/editors: All translators, and the editors too, are junior scholars, therefore in a less powerful position as compared to the source and target cultures' discipline gatekeepers; 
- Audience: the audience is composed of academics, especially the younger generation, and a wider public including political activists.

All these elements may have an impact on the end product. The current dominant role of English may affect translated Italian texts through the phenomenon of interference, with English leaving its stamp on the lexicogrammatical choices made in target texts due to its greater prestige. Another factor that may lead to the preservation of the surface features of English originals is that junior scholars may be in awe of their authoritative sources and adopt a source-oriented approach. On the other hand, precisely because of their junior status, and the determination to make the international debate widely available in Italy, translators and editors may feel under pressure to produce texts that will be accepted by the receiving audience, a feature that may lead to a target-oriented approach to translation.

4.2 Design criteria in the compilation of the comparable corpus

The comparable corpus contains ten papers published in the journal Critica Marxista. The design criteria adopted in the selection of texts for the Critica Marxista (CM) corpus are illustrated in Table 1. In order to ensure maximal comparability with the original texts in English, the following aspects were controlled and, whenever possible, kept constant in the design of the corpus: type of text, authors, native speaker status, macro area of inquiry and discipline. Controlling these variables helps to reduce the potential influence of confounding factors in the study of writing cultures (Moreno 2008).

Table 1. Design criteria in the compilation of the comparable corpus.

\begin{tabular}{|c|c|c|}
\hline & Socialist Register (SR) & Critica Marxista $(\mathrm{CM})$ \\
\hline Type of text & Single-authored research articles & $\begin{array}{l}\text { Single-authored research } \\
\text { articles }\end{array}$ \\
\hline Authors & Academics & Academics \\
\hline Native speaker status & $\begin{array}{l}9 \text { native speakers/1 non-native } \\
\text { speaker }\end{array}$ & 10 native speakers \\
\hline Macro area & Political Studies & Political Studies \\
\hline Disciplines & $\begin{array}{l}\text { Political Economy (6), Sociology } \\
\text { (1), Anthropology (1), Labour } \\
\text { Studies (1), Politics (1) }\end{array}$ & $\begin{array}{l}\text { Political Economy (6), } \\
\text { Sociology (1), History of } \\
\text { Political Thought (3) }\end{array}$ \\
\hline
\end{tabular}

The texts contained within the comparable corpora are all single-authored articles. The authors of the SR corpus are academics working in various universities in the UK, USA, South Africa and Hong Kong, where the operating language is English. The authors of the CM corpus, on the other hand, are academics based in Italian universities, where the working language is Italian. The variety of geographical locations of English-speaking universities was not considered a factor that could greatly affect the results. In dealing with English, the notion of national culture becomes problematic given the international status of this language, especially in academic settings. Therefore, the texts in English gathered for this analysis are considered as reflecting the conventions of the international academic community.

The native speaker status of writers was ascertained by carrying out webbased investigations of the scholars' curriculum vitae and their institutional and personal web pages. In the SR corpus, nine articles are written by native speakers of English and one article is written by a non-native speaker. This text 
was retained because the author in question is based in a university in the UK and mainly uses English for publication purposes, as indicated in his list of publications available online. The authors of the papers in the CM corpus are all native speakers of Italian.

While corpus balance would be the ideal design requirement, it was not possible to achieve it fully. The macro area of enquiry is that of Political Studies. However, single contributions vary in terms of disciplinary perspective. Each corpus contains six articles in English and six articles in Italian by scholars form the field of Political Economy and one article, in both languages, from the field of Sociology. As for the remaining three articles, the SR corpus includes one paper from Anthropology, one from Labour Studies and one from the field of Politics. In the CM corpus the three remaining papers are all from the field of History of Political Thought.

Table 2. Quantitative information about the parallel and comparable corpora.

\begin{tabular}{lll}
\hline Corpora & Number of texts & Total number of words \\
\hline SR & 10 & 69,596 \\
SRI & 10 & 77,092 \\
CM & 10 & 49,494 \\
\hline
\end{tabular}

Table 2 provides quantitative information about the corpora. Because of differences in corpus size, the data will be presented in normalized form to facilitate comparison.

\subsection{Analytical procedure}

Reporting clauses with that/che-clause complementation were retrieved using the Concord Tool of WordSmith 6.0 (Scott 2011). The search words were that and che. A disambiguation process followed aiming at excluding irrelevant structures, namely relative pronouns (e.g. these were issues that; quello che, 'that which/the thing that'), nominal and adjectival predicates (e.g. the fact that, it is surprising that; il fatto che, 'the fact that', è vero che, 'it is true that'), nonfinite forms of reporting verbs (e.g. It was aimed at ensuring that; inutile dire che, 'needless to say that') and non-reporting patterns (e.g. in that, so that, to the extent that; nel senso che, 'in the sense that', a seconda che, 'depending on', oltre che, 'in addition to'). The remaining concordance lines were then examined qualitatively and quantitatively and results were compared.

Before presenting the quantitative data, it is necessary to introduce the classification scheme that was used for the analysis, as quantification occurred on the basis of the categories adopted to classify reporting clauses. Following Charles (2006), reporting clauses were analysed according to the source of the reported clause, the grammatical subject and the type of reporting verb (Table 3). Charles' category of it subjects, however, is relabelled here as 'impersonal' subjects in order to fit the bilingual nature of the data.

Table 3. Classification scheme adapted from Charles (2006: 497).

\begin{tabular}{ll}
\hline Source & Self-sourced reports: I have already noted that... \\
& Other-sourced research reports: Peter Gowan argued that... \\
& Other-sourced non-research reports: The Pentagon announced \\
& that... \\
Grammatical subject & Human: I will argue that... \\
& Non-human: The argument developed below suggests that... \\
& Impersonal $($ it $[$ English]/si and periphrastic passive constructions
\end{tabular}


Reporting verb ${ }^{7}$

[Italian]/clause as subject): It will be suggested that...

SAY verbs: e.g. argue, suggest, claim

THINK verbs: e.g. think, assume, believe

DISCOVER verbs: e.g. find, recognize, establish

SHOW verbs: e.g. mean, show, signal

Depending on whether reporting clauses are averrals or attributions, the source of the claim may be the writer (self-sourced reports) or other discourse participants, in which case, it is possible to distinguish between research sources (e.g. other scholars) or non-research sources (e.g. non-academic participants). Each of these types of sources can be expressed linguistically in three ways: 1) with a human subject, 2) with a non-human subject and 3) with impersonal constructions. In the case of human subjects, normally personal pronouns are used for averrals, whereas the proper names of other scholars or participants are employed in attributions. As for non-human subjects, metonymic expressions, such as study, are common in both averrals and attributions. The category of impersonal subjects is the most complex and varied one, because it can be expressed in different ways depending on the linguistic code. While in both English and Italian, entire clauses may occur in subject position, only the English language possesses structures with a dummy subject (i.e. $i t$ ) followed by the passive voice. On the other hand, in Italian the main impersonal form in reporting clauses is the so-called impersonal si, whose function is to make the semantic referent general and to impersonalise the verbal process (see Salvi 1991: 101-102) (example 10). ${ }^{8}$

(10) Si può ritenere che lo Stato sia presente a due livelli [...]. [CM4] "One can argue that the State is present at two levels [...]."

In reporting clauses, it is possible to identify a variety of reporting verbs, such as suggest, claim, show and find. Example (11) shows how the classification scheme was applied to reporting clauses.

\footnotetext{
${ }^{7}$ For the categories of verbs, Charles (2006) refers to the work of Francis et al. (1996), in which semantic groups are created based on grammatical patterns. In her study, Charles only includes the $V$-that semantic classes that are likely to be found in academic prose (excluding for instances SCREAM verbs). In Table 3, too, only these categories were included because very few data were retrieved for the other ones (i.e. up to a maximum of three raw instances of ADD verbs and six of ARRANGE verbs). It should be pointed out that Francis et al.'s semantic classification is based on English grammatical patterns. However, when analysing the Italian $V$-che pattern, those semantic groups seemed to be usefully applicable to the Italian data as well. Therefore, for the purposes of this study, Francis et al.'s classification scheme was considered satisfactory.

${ }^{8}$ In Italian there is another si construction, which is called passive si (Salvi 1991:102-103). While apparently displaying the same surface grammar as impersonal si forms, passive si constructions are only found with transitive verbs: the object of the verb functions as grammatical subject and controls verb agreement (e.g. Cosicché, fallito il procedimento di trasformazione, si sono ritenuti inesistenti $i$ valori [CM8], 'Therefore, when the transformation process failed, its values were considered inexistent"). By contrast, impersonal si can be used with transitive and intransitive verbs, and the verb is always conjugated in the third person singular (example 10 above). Passive si constructions cannot be used in reporting clauses with che complementation; therefore, they are not considered in this study.

${ }^{9}$ The translation provided in example (10) illustrates the impersonal structure of the reporting clause using one as subject. However, the reporting verb does not reflect the lexical choice made in the original text, where the verb ritenere literally means 'to consider', 'to reckon', 'to think'. Hence, to preserve that lexical choice, a more appropriate translation would be: 'The State can be considered as being present at two levels [...].".
} 
(11) In fact, I [HUMAN - SELF-SOURCED] will argue [SAY VERBS] that the economic weaknesses of the model can in large measure be explained by the kind of political alliance that was required to support it [...]. [SR5]

A concluding methodological note regards the criteria for quantification and normalization. These procedures were carried out calculating the frequency of occurrence of the items that and che. In this way the problem of how to deal with grammatical subjects or reporting verbs composed of more than one lexical item was avoided.

\section{Results}

\subsection{Source}

Table 4 shows the quantitative findings (raw and normalized data) related to the type of source for claims, i.e. self-sourced, other-sourced research and othersourced non-research reports.

Table 4. Source of that/che-clauses. Raw and normalized data per 10,000 words (pttw).

\begin{tabular}{lllllll}
\hline Source & $\begin{array}{l}\text { SR } \\
\text { (English } \\
\text { originals) }\end{array}$ & $\begin{array}{l}\text { SRI } \\
\text { (Italian } \\
\text { translations) }\end{array}$ & \multicolumn{2}{l}{$\begin{array}{l}\text { CM } \\
\text { (Italian originals) }\end{array}$} \\
\cline { 2 - 7 } & Raw & Norm. & Raw & Norm. & Raw & Norm. \\
\hline Self-sourced & 24 & 3.45 & 28 & 3.63 & 59 & 11.92 \\
Other-sourced research & 45 & 6.47 & 43 & 5.58 & 54 & 10.91 \\
Other-sourced non-research & 65 & 9.34 & 61 & 7.91 & 21 & 4.24 \\
Total & $\mathbf{1 3 4}$ & $\mathbf{1 9 . 2 5}$ & $\mathbf{1 3 2}$ & $\mathbf{1 7 . 1 2}$ & $\mathbf{1 3 4}$ & $\mathbf{2 7 . 0 7}$ \\
\hline
\end{tabular}

The distribution of types of source is similar in the SR and the SRI corpora: non-research sources constitute the largest portion of claim originators, followed by other-sourced research reports and self-sourced research reports. In the translated texts, however, the frequency of other-sourced research and nonresearch sources is slightly lower. In order to determine whether these differences are statistically significant, the chi-squared test was applied to the data. The results indicate that despite the apparent dissimilarities, the SR and SRI corpora do not differ in statistically significant ways in terms of type of source. ${ }^{10}$

In original Italian papers $(\mathrm{CM})$, on the other hand, not only are reporting che-clauses with verbal predicate more frequently used (i.e. $27.07 \mathrm{pttw} \mathrm{CM}$ vs. $19.25 \mathrm{pttw}$ in SR), but the distribution of sources of claims is different. Othersourced non-research reports are the least frequent type of source, while selfsourced and other-sourced research reports have rather similar frequencies, which more than double those of non-research sources. The chi-squared test confirms that the texts belonging to the $\mathrm{CM}$ corpus present distinctive features that make them significantly different from those of the SR and SRI corpora. ${ }^{11}$

\footnotetext{
${ }^{10}$ In language studies an acceptable cut-off point is a p-value of 0.05 (Ji and Oakes 2012:190). The result of the chi-squared test for SR by SRI is 0.4651 ; d.f. $=2$. The result is not significant at $\mathrm{p} \leq 0.05$.

${ }^{11}$ Chi-squared CM by SR $=38.0888$; d.f. 2; $\mathrm{p}<0.001$. Chi-squared CM by SRI = 31.7924; d.f. $2 ; \mathrm{p}<0.001$.
} 
The high number of non-research discourse participants in the SR and SRI corpora underscores the important role that real-world actors and interlocutors play in research published in English for an international audience. On the other hand, the greater reliance on self-sourced and other-sourced research reports in the $\mathrm{CM}$ corpus indicates that the discussion is chiefly based on the expression of the writer's position as compared to previous works, which are re-examined, reinterpreted and re-assessed. It is a form of scholarly inquiry less centred on the analysis of current socio-political phenomena and more focused on theoretical issues. Examples (12) and (13) illustrate these two research tendencies respectively.

(12) The defence minister, Geoff Hoon, admitted to the Hutton enquiry that he knew the report referred only to battlefield weapons [...]. [SR8]

(13) Molti autori che si sono occupati della 'trasformazione' ritengono che essa rappresenti l'esperimento cruciale [...] della teoria del valore di Marx [...]. [CM8]

"Many of the authors who have dealt with the 'transformation' believe that it represents the crucial experiment [...] of Marx's value theory [...]."

\subsection{Grammatical subject}

The normalized frequencies obtained for SR and CM (Table 5) suggest different distribution patterns in terms of grammatical subject, which are statistically significant. ${ }^{12}$ Impersonal subjects, which in Italian are realized by means of impersonal si constructions and clauses as subject, have a higher frequency in the $\mathrm{CM}$ corpus. However, impersonal subjects are by no means the most widely used type of subject in original Italian papers: human ones are the preferred category and nearly double those in SR (with a ratio of 1.8:1). Below I will investigate the association between subjects and source trying to shed some light on these differences.

The comparison between SR and SRI indicates that the translated texts feature fewer human and non-human subjects, but a greater number of impersonal subjects; there are almost twice as many in SRI. Impersonal subjects are all expressed by means of impersonal si constructions, a feature which is very common in academic texts in Italian. The chi-squared test indicates that the differences in distribution patterns of grammatical subject between SR and SRI are statistically significant. ${ }^{13}$ The translated texts, however, also differ in significant ways from original Italian texts: the most remarkable difference concerns the use of human subjects which are less frequent in the SRI corpus, probably due to the configuration of the argument in the source texts. ${ }^{14}$

\footnotetext{
12 Chi-squared SR by $\mathrm{CM}=22.7581 ;$ d.f. $=2 ; \mathrm{p}<0.001$.

${ }^{13}$ Chi-squared SR by SRI $=9.69$; d.f. $=2$. The result is significant at $\mathrm{p}<0.01$.

${ }^{14}$ Chi-squared SRI by $\mathrm{CM}=15.7262$; d.f. $=2 ; \mathrm{p}<0.001$.
} 
Table 5. Grammatical subject in that/che-clauses. Raw and normalized data per 10,000 words (pttw).

\begin{tabular}{lllllll}
\hline Grammatical subject & $\begin{array}{l}\text { SR } \\
\text { (English } \\
\text { originals) }\end{array}$ & $\begin{array}{l}\text { SRI } \\
\text { (Italian } \\
\text { translations) }\end{array}$ & $\begin{array}{l}\text { CM } \\
\text { (Italian } \\
\text { originals) }\end{array}$ \\
\cline { 2 - 7 } & Raw & Norm. & Raw & Norm. & Raw & Norm. \\
\hline Human & 64 & 9.20 & 52 & 6.75 & 81 & 16.37 \\
Non-human & 53 & 7.62 & 43 & 5.58 & 19 & 3.84 \\
Impersonal subject & 17 & 2.44 & 37 & 4.80 & 34 & 6.87 \\
Total & $\mathbf{1 3 4}$ & $\mathbf{1 9 . 2 5}$ & $\mathbf{1 3 2}$ & $\mathbf{1 7 . 1 2}$ & $\mathbf{1 3 4}$ & $\mathbf{2 7 . 0 7}$ \\
\hline
\end{tabular}

In order to complement these results, the data for grammatical subject were crossed with the sources of reporting clauses to investigate which type of referent more often corresponds to human, non-human and impersonal subjects. The results of these combinations are reported in Tables 6-8.

Table 6. Human subjects by source. Raw and normalized data per 10,000 words (pttw).

\begin{tabular}{|c|c|c|c|c|c|c|}
\hline \multicolumn{7}{|l|}{ Human subjects } \\
\hline \multirow[t]{2}{*}{ Source } & \multicolumn{2}{|c|}{$\begin{array}{l}\text { SR } \\
\text { (English } \\
\text { originals) }\end{array}$} & \multicolumn{2}{|c|}{$\begin{array}{l}\text { SRI } \\
\text { (Italian } \\
\text { translations) }\end{array}$} & \multicolumn{2}{|c|}{$\begin{array}{l}\text { CM } \\
\text { (Italian } \\
\text { originals) }\end{array}$} \\
\hline & Raw & Norm. & Raw & Norm. & Raw & Norm. \\
\hline Self-sourced reports & 10 & 1.44 & 7 & 0.91 & 32 & 6.47 \\
\hline Other-sourced research & 32 & 4.60 & 24 & 3.11 & 45 & 9.09 \\
\hline Other-sourced non-research & 22 & 3.16 & 21 & 2.72 & 4 & 0.81 \\
\hline Total & 64 & 9.20 & 52 & 6.75 & 81 & 16.37 \\
\hline
\end{tabular}

Human subjects (Table 6) are the most frequent type of subject in other-sourced research reports in all the three corpora, although the frequencies are different, with the CM corpus featuring the highest number of occurrences $(9.09 \mathrm{pttw})$. The high frequency of human subjects for other-sourced research reports in CM is almost exclusively due to the use of integral citations, as illustrated in example (14). Once again, this seems to indicate a greater tendency to report ideas from the existing literature in the $\mathrm{CM}$ corpus:

(14) Ed aggiunge, sbagliando, che Marx "non da una risposta precisa in nessun luogo della sua opera". [CM7]

"And he adds, mistakenly, that Marx 'does not provide any specific answer in any of his works'."

In original Italian texts, human subjects also tend to correlate with self-sourced reports, while in the SR/SRI corpora this association is less noticeable. The grammatical form chosen is most often the first person plural subject noi ('we') ( 25 instances vs. 7 hits of the first person singular form). The referent of the plural form can be interpreted as including the author and the readers, thus diminishing the level of writer visibility and acting as a form of reader engagement (Hyland 2005). These instances of inclusive references occur when the writer involves the audience in hypothetical lines of reasoning, pulling readers along with the unfolding argument. Among the verbs used in association with inclusive references are ammettere ('admit'), concludere ('conclude') and supporre ('suppose'). However, in some instances, the sole reasonable referent seems to be the author, as the action expressed by the verb can only be accomplished by the person performing the speech act (e.g. abbiamo infatti 
argomentato che [...]. [CM3], "indeed we have argued that..."). Both the use of inclusive plural subjects and the so-called pluralis majestatis are quite typical of academic writing in Italian. According to Umberto Eco (2002 [1977]:168, my translation), "we' is used because what is stated is assumed to be shared by readers. Writing is a social act: I am writing so that you, the reader, will accept what I am putting forward."15

In the texts of the SR and SRI corpora, human subjects feature more frequently in other-sourced non-research reports than in self-sourced reports. This result may support the interpretation of discrepancies as related to different research agendas, with the international debate revolving around specific social, political and economic issues; however, it may also indicate a minor use of thatclauses as structures to express writer/reader visibility. It should be observed that the use of reporting constructions for self-sourced reports is a phenomenon that may be subjective, as noticed by Charles (2006:505). Therefore, more data are needed to clarify this issue.

Table 7 shows the use of impersonal subjects across types of sources. There seems to be a greater tendency by Italian writers to employ impersonal subject, particularly in self-sourced reports, which in the CM corpus occur 5.46 times pttw while in the SR corpus 1.72 times pttw. The translated texts lie in between, with 2.33 occurrences pttw. Since a slight increase in impersonal references is noticeable in the SRI corpus across all types of sources, it seems that translators have extended the practice of reducing participant visibility to all forms of reports. In addition, impersonal subjects in SRI exclusively include $s i$ constructions. An example is given in (15), where the si form is used to report ideas from the literature, a choice that is uncommon in CM. Once again, the frequencies obtained are low; therefore this apparent tendency needs to be tested in a larger sample of texts.

(15) Di fatto, in alcuni studi sulla politica economica turca si sostiene che [...]. [SRI4]

"In fact, in studies of Turkish economic policy it is argued that [...]."

[Back-translation]

In fact, in studies of Turkish economic policy, one comes across the argument that [...] [Original source text version - SR4]

Table 7. Impersonal subjects by source. Raw and normalized data per 10,000 words (pttw).

\begin{tabular}{|c|c|c|c|c|c|c|}
\hline \multicolumn{7}{|l|}{ Impersonal subjects } \\
\hline \multirow[t]{2}{*}{ Source } & \multicolumn{2}{|c|}{$\begin{array}{l}\text { SR } \\
\text { (English } \\
\text { originals) }\end{array}$} & \multicolumn{2}{|c|}{$\begin{array}{l}\text { SRI } \\
\text { (Italian } \\
\text { translations) }\end{array}$} & \multicolumn{2}{|c|}{$\begin{array}{l}\text { CM } \\
\text { (Italian } \\
\text { originals) } \\
\end{array}$} \\
\hline & Raw & Norm. & Raw & Norm. & Raw & Norm. \\
\hline Self-sourced reports & 12 & 1.72 & 18 & 2.33 & 27 & 5.46 \\
\hline Other-source research & 4 & 0.57 & 11 & 1.43 & 1 & 0.20 \\
\hline Other-sourced non-research & 1 & 0.14 & 8 & 1.04 & 6 & 1.21 \\
\hline Total & 17 & 2.44 & 37 & 4.80 & 34 & 6.87 \\
\hline
\end{tabular}

As regards non-human subjects (Table 8), they are most often used in othersourced non-research reports in all the three corpora examined. However, the

\footnotetext{
${ }^{15}$ The original Italian version is: 'Si dice 'noi' perché si presume che quello che si afferma possa essere condiviso dai lettori. Scrivere è un atto sociale: io scrivo affinché tu che leggi accetti quello che io ti propongo".
} 
data suggest a larger use of this category in the SR corpus than in the CM corpus. The SRI corpus seems to lie in between the two, partly reflecting the source texts' research orientation in favour of the analysis of real-world phenomena, as illustrated in example (16).

(16) Questo perché una campagna decennale e piuttosto intensa condotta dal capitale nazionale aveva già chiarito che un regime di pianificazione non sarebbe stato tollerato. [SRI5]

This was because a decade-long, and quite intense, campaign by domestic capital had already made it clear that a planning regime would not be tolerated. [Original source text version - SR5]

Table 8. Non-human subjects by source. Raw and normalized data per 10,000 words (pptw).

\begin{tabular}{lllllll}
\hline Non-human subjects & \multicolumn{4}{l}{} & & \\
\hline Source & $\begin{array}{l}\text { SR } \\
\text { (English } \\
\text { originals) }\end{array}$ & $\begin{array}{l}\text { SRI } \\
\text { (Italian } \\
\text { translations) }\end{array}$ & $\begin{array}{l}\text { CM } \\
\text { (Italian } \\
\text { originals) }\end{array}$ \\
\cline { 2 - 8 } & Raw & Norm. & Raw & Norm. & Raw & Norm. \\
\hline Self-sourced reports & 2 & 0.29 & 3 & 0.39 & 0 & 0 \\
Other-source research & 9 & 1.29 & 8 & 1.04 & 8 & 1.62 \\
Other-sourced non-research & 42 & 6.03 & 32 & 4.15 & 11 & 2.22 \\
Total & $\mathbf{5 3}$ & $\mathbf{7 . 6 2}$ & $\mathbf{4 3}$ & $\mathbf{5 . 5 8}$ & $\mathbf{1 9}$ & $\mathbf{3 . 8 4}$ \\
\hline
\end{tabular}

The slight decrease in non-human subjects for non-research reports in the SRI corpus is difficult to explain on the basis of a comparison with the CM corpus' frequency data: on the one hand, the low frequencies make any generalization hazardous; on the other hand, a more qualitative analysis focusing on how each source text instance was translated would be necessary to account for this difference.

\subsection{Type of verb}

Table 9 shows the raw and normalized frequencies of the types of verb in reporting clauses with that/che-complementiser across the three corpora.

Table 9. Type of reporting verb. Raw and normalized data per 10,000 words (pttw).

\begin{tabular}{lllllll}
\hline Type of verb & \multicolumn{2}{l}{$\begin{array}{l}\text { SR } \\
\text { (English originals) }\end{array}$} & \multicolumn{2}{l}{$\begin{array}{l}\text { SRI } \\
\text { (Italian }\end{array}$} & \multicolumn{3}{l}{ translations) } & \multicolumn{2}{l}{$\begin{array}{l}\text { CM } \\
\text { (Italian originals) }\end{array}$} \\
& Raw & Norm. & Raw & Norm. & Raw & Norm. \\
\hline SAY & 79 & 11.35 & 73 & 9.45 & 70 & 14.14 \\
SHOW & 28 & 4.02 & 21 & 2.72 & 12 & 2.42 \\
DISCOVER & 11 & 1.58 & 4 & 0.52 & 4 & 0.81 \\
THINK & 8 & 1.15 & 32 & 4.15 & 42 & 8.49 \\
\hline
\end{tabular}

SAY verbs are the most common type of verb in the three sets of texts, with the highest frequency in the CM corpus (14.14 pttw), followed by the SR corpus (11.35 pttw) and the SRI corpus (9.45 pttw). This preference may be a disciplinary one. Hyland (2000:27) notes that research papers in the Social Sciences and Humanities, such as Philosophy, Sociology and Applied Linguistics, favour reporting verbs performing discourse acts, such as say, argue and suggest.

As regards the remaining instances, the data for SHOW and DISCOVER verbs are too sparse for any clear tendencies to emerge. The frequencies for THINK verbs too are low, and a larger corpus is undoubtedly needed. In particular, 
further research should seek to verify whether the target language plays a role in the use of this category of reporting verb. Indeed THINK verbs are the second most frequent class of verbs in both CM (8.49 pttw) and SRI (4.15 pttw), but not so in SR, where they occur more sparingly (1.15 pttw). This discrepancy indicates that in the SRI corpus some cognitive verbs were introduced anew by the translators, as shown in example (17). These items are pensare ('to think') (seven occurrences in SRI vs. one occurrence of the verb think in SR) and ritenere ('to believe') (eight occurrences in SRI vs. one occurrence of the verb believe in SR); but other verbs appear as well, such as credere ('to believe'), stimare ('to consider') and dare per scontato ('to take for granted').

(17) Alcuni hanno ritenuto che la cosa essenziale fosse ristabilire 1' integrità territoriale' su scala nazionale [...]. [SRI1]

"Some believed that the essential thing was to re-establish "territorial integrity' at the national scale [...]." [Back-translation]

For some, it has been imperative to re-establish 'territorial integrity' at the national scale [...]. [Original source text version - SR1]

The lexical inventory of THINK verbs in the SRI corpus, however, differs from that of the CM corpus in terms of variation and meaning. The original Italian texts contain not only verbs of opinion, but also verbs related to mental research activities involving hypothesis formulation, deductive reasoning and speculation. Examples are immaginare ('to imagine'), supporre ('to suppose/assume'), ipotizzare ('to hypothesise'), all verbs which are generally associated with human subjects and which occur mostly in other-sourced research reports and self-sourced constructions. As regards averrals, in particular, the SRI corpus also differs from the CM corpus in terms of the level of personality. In CM, the subject of averred cognitive activities is always a plural collective referent, i.e. noi, 'we'. In SRI, on the other hand, only two averrals by means of a cognitive verb include a human subject (i.e. io, 'I'), while the rest feature an impersonal si subject, thus conveying a more detached stance.

\section{Discussion}

Given the relatively few cases of reporting clauses with that/checomplementation examined, any straightforward generalization about a correlation between the distributions observed and specific epistemological inclinations of whole academic communities should be avoided. Due to the small size of the corpora, the differences observed could also be related to the preferences of specific disciplinary domains, the choices made by individual writers in the SR and CM corpora as well as those made by translators in the SRI corpus. The results obtained here, therefore, should be regarded as possible tendencies to be verified in larger corpora.

Scrutinising the sources of claims, i.e. whether they are self-sourced, other-sourced research and other-sourced non-research reports, it appears that papers in English are more focused on real-world participants, as revealed by the predominance of other-sourced non-research reports. This result is in line with Charles (2006:498) who found that, when compared to research in Materials Sciences, studies in Politics (by English native speakers) showed a more extensive use of non-research sources, because they dealt with political actors and entities. By contrast, in original Italian papers, most reports are 
attributed to the writers themselves or to other scholars, suggesting a greater preoccupation with the examination of existing theoretical positions, towards which writers take a stance. These discrepancies seem to hint at divergent research agendas within the international and the Italian academic communities.

The source of claims is the feature that is less likely to change in translation. This is not surprising if we consider that the distribution of sources pertains to the ideational dimension of discourse, i.e. the topic that is being talked about or, in this case, the participants whose voice is being reported. Indeed, the distribution of type of source in translated texts was found not to diverge in statistically significant ways from that of original texts in English, but was shown to do so when compared to the distribution in non-translated Italian texts. This result indicates that translation can be regarded as a tool to import new research approaches which may integrate or even challenge the target academic culture's prevalent epistemology.

Statistically significant differences between original English and Italian papers were also observed in terms of the distribution of grammatical subjects. The most notable divergence pertains to human subjects, which in the CM corpus are almost twice as frequent as those in the SR corpus. This discrepancy is mainly due to the more frequent use of human subjects in self-sourced reports in $\mathrm{CM}$, most of which (i.e. 25 raw hits out of 32) feature an inclusive plural referent (i.e. noi, 'we'). By contrast, in SR human self-sourced reports are less frequent and plural inclusive referents are quite rare (only four raw occurrences). Reader visibility is a phenomenon that has been shown to vary across writing cultures and that may be related to the audience. Mur Dueñas (2011), for instance, found that Anglo-American scholars use inclusive authorial references less often than Spanish academics. Her interpretation is that Spanish scholars are aware of addressing a rather small and homogeneous audience, which makes them more inclined to appeal to mutual understanding. The same interpretation may hold true for the CM texts, given that Critica Marxista is one of the few journals available in Italy publishing research from the standpoint of a Marxist critique to Neoliberalism.

When translating the SR texts, translators were not faced with a homogenous audience, since the public that they aimed at was large and multifaceted. In addition, the source texts, having been written for an international audience, probably did not lend themselves to the introduction of a more reader-oriented interactional style. Therefore, not only was no new inclusive reference added, but the most notable result is that, overall, the SRI papers seem more impersonal than their source texts, at least when it comes to reporting clauses. This impression is mainly due to the higher number of impersonal subjects in SRI than in SR. All the impersonal subjects in SRI are expressed through si constructions, following the requirements of formal Italian writing. However, in contrast to original Italian papers, si forms are not only employed in averrals but also in attributions. Hence, it seems that si structures have been extended to uses that are not so widespread in the target language. It can therefore be suggested that the more frequent use of impersonal si constructions relates to the phenomenon of 'normalization' (Baker 1993), one of the 'universals' of translation, whereby the most salient features of the target language are overused, creating more standardised texts. In this case, it is the often-perceived preference for a detached and impersonal writing style in Italian 
(Bazzanella 1991) that is extended to claims that would not normally be formulated with impersonal si subjects.

Finally, with regard to the type of verb, all corpora show a preference for SAY verbs, a feature that can be attributed to the influence of the broad disciplinary filed, i.e. that of the Social Sciences. Nevertheless, differences can be noted between CM and SR particularly for the category of THINK verbs, which is much more frequent in CM. This difference may be related to the more prominent use of self-sourced reports in CM noted above. However, the frequency of cognitive verbs is also higher in the translated texts, with instances being added when they were not present in the source texts, and not necessarily in averrals, see example (17). Cognitive verbs, therefore, are likely to be perceived as an established way of reporting claims in Italian. Hence, in the case of the lexical choices of reporting verbs, the target language and culture are likely to play a role.

\section{Concluding remarks}

This study has offered an analysis of reporting that/che clauses in academic writing showing that these constructions may provide insights into different writing conventions and research orientations. Reporting clauses are therefore valuable constructions to investigate when exploring negotiation in the way claims are formulated. The source of claims, the choice of grammatical subject and the use of reporting verbs all appear interesting analytical foci for the investigation of epistemological inclinations and academic writing preferences.

It was noted that lexical and grammatical choices are likely to vary in translation, mainly under the influence of the target language and culture. Normalization strategies were observed which might respond to the need to avoid the risk of producing texts that are regarded as nonstandard and therefore rejected. In the case of academic translation, 'risk aversion' (Pym 2008:313) may be sought to guarantee acceptance for the claims made in the translated texts. In the Introduction to Socialist Register Italia, Adduci and Cerimele (2009:9) declare that with their project they hoped to address a new generation of intellectuals, both within academia and beyond, enabling those who lack English language competence to access the discussions at the international level. It appears therefore that opting for an established formal writing style was regarded as a strategy to secure the publication and the positive reception of the texts.

A final remark regards the role of English as the recognized language of international scholarly inquiry. It was hypothesised that due to the greater prestige of this language, the Italian translations could show signs of its influence. The results of this study, to be tested against larger sets of data, seem to suggest that linguistic and cultural prestige are likely to interact with other contextual forces. As shown here, the need to successfully introduce new research paradigms within a community where national writing traditions are strong and in which one is not yet a senior member may be examples of such competing drives. 


\section{References}

Acquaviva, P. 1991. Frasi argomentali: completive e soggettive. In Grande grammatica italiana di consultazione, Vol. II, L. Renzi and G. Salvi, G. (eds), 633-674. Bologna: il Mulino.

Adduci, M. and Cerimele M. 2009. Socialist Register Italia. Milano: Edizioni Punto Rosso.

Baker, M. 1993. Corpus Linguistics and Translation Studies: Implications and Applications. In Text and Technology: In Honour of John Sinclair, M. Baker, G. Francis, and E. Tognini-Bonelli (eds), 233-252. Amsterdam: John Benjamins.

Bazzanella, C. 1991. Il passivo personale con e senza cancellazione dell'agente: verso un approccio multidimensionale. In Tra rinascimento e strutture attuali: Saggi di linguistica italiana (Atti del primo convegno della Società Internazionale di Linguistica e Filologia Italiana, Siena, 28-31 marzo 1989, vol. 1), L. Giannelli, N. Maraschio, T. Poggi Salani and M. Vedovelli (eds), 373-385. Torino: Rosenberg \& Sellier.

Becher, T. 1981. Towards a Definition of Disciplinary Cultures. Studies in Higher Education 6(2): 109-122.

Bennett, K. 2007. Epistemicide! The Tale of a Predatory Discourse. The Translator 13(2): 151-169.

Biber, D., Johanasson S., Leech G., Conrad S. and Finegan E. (eds) (1999). The Longman Grammar of Spoken and Written English. London: Longman.

Biber, D. 1999. A Register Perspective on Grammar and Discourse: Variability in the Form and Use of English Complement Clauses. Discourse Studies 1(2): 131-150.

Calaresu, E. 2004. Testuali parole. La dimensione pragmatica e testuale del discorso riportato. Milano: Franco Angeli.

Charles M. 2006. The Construction of Stance in Reporting Clauses: A Crossdisciplinary Study of Theses. Applied Linguistics 27(3): 492-518.

Dor, D. 2005. Towards a Semantic Account of That-Deletion in English. Linguistics 43(2): 345-382.

Dressen, D. (2003). Geologists' Implicit Persuasive Strategies and the Construction of Evaluative Evidence. Journal of English for Academic Purposes 2(4): 273-290.

Eco, U. 2002 [1977]. Come si fa una tesi di laurea. Milano: Bompiani.

Elsness, J. 1984. That or Zero? A Look at the Choice of Object Clause Connective in a Corpus of American English. English Studies 65(6): 519533.

Francis, G., Hunston, S. and Manning, E. 1996. Collins COBUILD Grammar Patterns 1: Verbs. London: HarperCollins.

Hyland, K. 2000. Disciplinary Discourses: Social Interactions in Academic Writing. London: Longman.

Hyland, K. 2005. Stance and Engagement: A Model of Interaction in Academic Discourse. Discourse Studies 7(2): 173-192.

Hyland, K. and Tse, P. 2005. Hooking the Reader: A Corpus Study of Evaluative That in Abstracts. English for Specific Purposes 24(2): 123139.

Ji, M. and Oakes, M.P. 2012. A Corpus study of early English translations of Cao Xueqin's Hongloumeng. In Quantitative Methods in Corpus-Based 
Translation Studies. A Practical Guide to Descriptive Translation Research, M.P. Oakes and M. Ji (eds), 177-208. Amsterdam: Benjamins.

Kaltenböck, G. 2006. 'That is the Question': Complementizer Omission in Extraposed that-Clauses. English Language and Linguistics 10(2): 371-396.

MacDonald, S.P. 1994. Professional Academic Writing in the Humanities and Social Sciences. Carbondale and Edwardsville: Southern Illinois University Press.

Martínez, I.A. 2005. Native and Non-Native Writer's Use of First Person Pronouns in the Different Sections of Biology Research Articles in English. Journal of Second Language Writing 14(3): 174-190.

Molino, A. 2010. Personal and Impersonal Authorial References: A Contrastive Study of English and Italian Linguistics Research Articles. Journal of English for Academic Purposes 9(2): 86-101.

Moreno, A.I. 2008. The Importance of Comparable Corpora in Cross-Cultural Studies. In Contrastive Rhetoric: Reaching to Intercultural Rhetoric, U. Connor, E. Nagelhout and W Rozycki (eds), 25-41. Amsterdam: John Benjamins.

Mortara Garavelli, B. 1995. Il discorso riportato. In Grande grammatica italiana di consultazione, Vol. III, L. Renzi, G. Salvi and A. Cardinaletti (eds), 427-470. Bologna: il Mulino.

Mur Dueñas, P. 2007. 'I/we focus on': A Cross-Cultural Analysis of SelfMentions in Business Management Research Articles. Journal of English for Academic Purposes 6(2): 143-162.

Mur Dueñas, P. 2011. An Intercultural Analysis of Metadiscourse Features in Research Articles Written in English and in Spanish. Journal of Pragmatics 43(12), 3068-3079.

Murphy, A.C. 2005. Markers of Attribution in English and Italian Opinion Articles: A Comparative Corpus-Based Study. ICAME Journal 29: 131-150.

Olohan, M. 2001. Spelling out the Optionals in Translation: A Corpus Study. UCREL Technical Papers 13: 423-432.

Olohan, M. 2002. Leave it out! Using a Comparable Corpus to Investigate Aspects of Explicitation in Translation. Cadernos de Tradução IX: 153-169.

Olohan, M. and Baker, M. 2000. Reporting That in Translated English. Evidence for Subconscious Processes of Explicitation? Across Languages and Cultures 1(2): 141-158.

Pérez-Llantada, C. 2012. Scientific Discourse and the Rhetoric of Globalization: The Impact of Culture and Language. Continuum: London.

Pym, A. 2008. On Toury's Laws of How Translators Translate. In Beyond Descriptive Translation Studies, A. Pym, M. Shlesinger and D. Simeoni (eds), 311-328. Amsterdam: John Benjamins.

Renzi, L. and Salvi, G. (eds). 1991. Grande grammatica italiana di consultazione, Vol. II. Bologna: il Mulino.

Renzi, L., Salvi, G. and Cardinaletti, A. (eds). 1995. Grande grammatica italiana di consultazione, Vol. III. Bologna: il Mulino.

Salvi, G. 1991. [1988]. La frase semplice. In Grande grammatica italiana di consultazione, Vol. I., L. Renzi (ed.), 29-114. Bologna: il Mulino. 
Scott, M. 2011. WordSmith Tools (Version 6.0). Liverpool: Lexical Analysis Software.

Storms, G. 1966. That-clauses in Modern English. English Studies 47(1-6): 249270.

Suárez, L. and Moreno, A. 2008. The Rhetorical Structure of Academic Book Reviews of Literature. In Contrastive Rhetoric: Reaching to Intercultural Rhetoric, U. Connor, E. Nagelhout and W. Rozycki (eds), 147-165. Philadelphia: John Benjamins.

Tadros, A. 1993. The Pragmatics of Text Averral and Attribution in Academic texts. In Data, description, discourse, M. Hoey (ed.), 98-114. London: HarperCollins.

Thompson, S.A. and Mulac, A. 1991. The Discourse Conditions for the Use of the Complementizer that in Conversational English. Journal of Pragmatics 15(3): 237-251.

Wanner, D. 1981. Surface Complementizer Deletion: Italian che - $\varnothing$. Journal of Italian Linguistics 6(1): 47-82.

Wandruszka, U. 1991. Frasi subordinate al congiuntivo. In Grande grammatica italiana di consultazione, Vol. II, L. Renzi and G. Salvi (eds), 415-482. Bologna: il Mulino.

Author's address

Alessandra Molino

Department of Foreign Languages and Literature and Modern Cultures University of Turin

Via Verdi 10

10124

Torino

Italy

alessandra.molino@unito.it

\section{Appendix A - Socialist Register Corpus (SR)}

Albo, G. 2007. The Limits of Eco-Localism: Scale, Strategy, Socialism. Socialist Register: Coming to Terms with Nature 43, L. Panitch and C. Leys (eds), 337-363. London: Merlin Press. [SR1]

Albo, G. 2008. Neoliberalism and the Discontented. Socialist Register: Global Flashpoints 44, L. Panitch and C. Leys (eds), 354-362. London: Merlin Press. [SR2]

Bond, P. 2005. US Empire and South African Subimperialism. Socialist Register: The Empire Reloaded 41, L. Panitch and C. Leys (eds), 218-238. London: Merlin Press. [SR3]

Cammack, P. 2005. 'Signs of the Times': Capitalism, Competitiveness, and the New Face of Empire in Latin America. Socialist Register: The Empire 
Reloaded 41, L. Panitch and C. Leys (eds), 256-270. London: Merlin Press. [SR4]

Chibber, V. 2005. Reviving the Developmental State? The Myth of the 'National Bourgeoisie'. Socialist Register: The Empire Reloaded 41, L. Panitch and C. Leys (eds), 144-165. London: Merlin Press. [SR5]

Grahl, J. 2005. The European Union and American Power. Socialist Register: The Empire Reloaded 41, L. Panitch and C. Leys (eds), 284-300. London: Merlin Press. [SR6]

Huws, U. 2001. The Making of a Cybertariat? Virtual Work in a Real World. Socialist Register: Working Classes, Global Realities 37, L. Panitch and C. Leys (eds), 1-23. London: Merlin Press. [SR7]

Leys, C. 2006. The cynical state. Socialist Register: Telling the Truth 42, L. Panitch and C. Leys (eds), 1-27. London: Merlin Press. [SR8]

Saad-Filho, A. 2008. Marxian and Keynesian Critiques of Neoliberalism. Socialist Register: Global Flashpoints 44, L. Panitch and C. Leys (eds), 337-345. London: Merlin Press. [SR9]

Smith, N. 2007. Nature as Accumulation Strategy. Socialist Register: Coming to Terms with Nature 43, L. Panitch and C. Leys (eds), 18-36. London: Merlin Press. [SR10]

\section{Appendix B - Socialist Register Italia Corpus (SRI)}

Albo, G. 2007. I limiti dell'ecolocalismo: scala, strategia e socialismo. In Socialist Register Italia: Antologia (2001-2008), M. Adduci and M. Cerimele (eds), 269-298. Milano: Edizioni Punto Rosso. [SRI1]

Albo, G. 2008. Il neoliberismo e i suoi oppositori. In Socialist Register Italia: Antologia (2001-2008), M. Adduci and M. Cerimele (eds), 345-355. Milano: Edizioni Punto Rosso. [SRI2]

Bond, P. 2005. L'Impero americano e il subimperialismo sudafricano. In Socialist Register Italia: Antologia (2001-2008), M. Adduci and M. Cerimele (eds), 108-132. Milano: Edizioni Punto Rosso. [SRI3]

Cammack, P. 2005. 'Segni dei tempi': capitalismo, competitività, e il nuovo volto dell'Impero in America Latina. In Socialist Register Italia: Antologia (2001-2008), M. Adduci and M. Cerimele (eds), 133-145. Milano: Edizioni Punto Rosso. [SRI4]

Chibber, V. 2005. Risuscitare lo Stato sviluppista? Il mito della 'borghesia nazionale'. In Socialist Register Italia: Antologia (2001-2008), M. Adduci and M. Cerimele (eds), 150-175. Milano: Edizioni Punto Rosso. [SRI5]

Grahl, J. 2005. Il potere di Unione europea e Stati uniti a confronto. In Socialist Register Italia: Antologia (2001-2008), M. Adduci and M. Cerimele (eds), 176-194. Milano: Edizioni Punto Rosso. [SRI6]

Huws, U. 2001. La nascita del cibertariato? Il lavoro virtuale in un mondo reale. In Socialist Register Italia: Antologia (2001-2008), M. Adduci and M. Cerimele (eds), 37-66. Milano: Edizioni Punto Rosso. [SRI7]

Leys, Colin (2006). Lo Stato cinico. In Socialist Register Italia: Antologia (2001-2008), M. Adduci and M. Cerimele (eds), 238-268. Milano: Edizioni Punto Rosso. [SRI8]

Saad-Filho, Alfredo (2008). Il neoliberismo: prospettive di critica marxista e keynesiana. In Socialist Register Italia: Antologia (2001-2008), M. 
Adduci and M. Cerimele (eds), 325-335. Milano: Edizioni Punto Rosso. [SRI9]

Smith, N. 2007. La natura come strategia di accumulazione. In Socialist Register Italia: Antologia (2001-2008), M. Adduci and M. Cerimele (eds), 299-322. Milano: Edizioni Punto Rosso. [SRI10]

\section{Appendix C - Critica Marxista Corpus (CM)}

Bellanca, N. 2003. Comunismo, contratto di lavoro, sfruttamento. Per un ripensamento della teoria economica marxista. Critica Marxista 2: 68-78. [CM1]

Bellanca, N. 2008. Il capitalismo e oltre: sull'attualità di Marx. Critica Marxista 4: 69-77. [CM2]

Carchedi, G. 2007. Sulle inconsistenze logiche della teoria della forma valore. Critica Marxista 2: 47-55. [CM3]

Cesaratto, S. 2007. Stato sociale e teoria 'classica' della distribuzione. Critica Marxista 1: 35-43. [CM4]

Colacicco, M. 2008. Crisi, Europa, traducibilità. Antonio Gramsci in contrappunto. Critica Marxista 2/3: 84-93. [CM5]

Liguori, G. 2006. Il marxismo italiano tra teoria e politica. Critica marxista 1963-1991. Critica Marxista 1: 27-36. [CM6]

Mazzetti, G. 2001. Lo sfruttamento è davvero anacronistico? Critica Marxista 1: 29-43. [CM7]

Perri, S. 2002. La teoria del neovalore. Critica Marxista 2: 67-77. [CM8]

Ragona, G. 2005. Tecnici, oligarchie e socialismo. Rubel lettore di Burnham. Critica Marxista 6: 65-72. [CM9]

Suppa, S. 2008. Nazionale, internazionale, forme dell'egemonia in Gramsci. Critica Marxista 2/3: 44-50. [CM10] 